\title{
Comparative analysis of data availability and data requirements for efficient management and control of future distribution networks
}

\author{
Document Version \\ Accepted author manuscript
}

Link to publication record in Manchester Research Explorer

Citation for published version (APA):

Ponocko, J., \& Milanovic, J. V. (2016). Comparative analysis of data availability and data requirements for efficient management and control of future distribution networks. In IET Conference Publications (CP711 ed., Vol. 2016). Institution of Engineering and Technology .

\section{Published in:}

IET Conference Publications

\section{Citing this paper}

Please note that where the full-text provided on Manchester Research Explorer is the Author Accepted Manuscript or Proof version this may differ from the final Published version. If citing, it is advised that you check and use the publisher's definitive version.

\section{General rights}

Copyright and moral rights for the publications made accessible in the Research Explorer are retained by the authors and/or other copyright owners and it is a condition of accessing publications that users recognise and abide by the legal requirements associated with these rights.

\section{Takedown policy}

If you believe that this document breaches copyright please refer to the University of Manchester's Takedown Procedures [http://man.ac.uk/04Y6Bo] or contact uml.scholarlycommunications@manchester.ac.uk providing relevant details, so we can investigate your claim.

\section{OPEN ACCESS}




\title{
COMPARATIVE ANALYSIS OF DATA AVAILABILITY AND DATA REQUIREMENTS FOR EFFICIENT MANAGEMENT AND CONTROL OF FUTURE DISTRIBUTION NETWORKS
}

\author{
Jelena Ponoćko ${ }^{*}$, Jovica V. Milanovic ${ }^{1}$ \\ ${ }^{1}$ Electrical Energy and Power Systems Group, University of Manchester, Manchester, UK \\ *jelena.ponocko@manchester.ac.uk
}

Keywords: distribution network, data analytics, smart meter, smart grid.

\begin{abstract}
This paper starts by discussing the data requirements for efficient control and management of future power networks and justifies the need for different types of data. It then compares the data requirements with presently available or routinely collected data by distribution system operators (DSOs) and identifies the mismatch between the two. Finally, considering growing deployment and increasing reliance on smart meters, it presents an overview of the technical specifications of typical commercially available smart meters and discusses the possibilities of information retrieval from the data provided by smart meters. The results of this analysis illustrate to what extent the existing smart meters can support demand side management (DSM) and identify what additional functionalities smart meters should have in order to facilitate envisaged services.
\end{abstract}

\section{Introduction}

With the increasing complexity of modern distribution power systems, the size of deployed monitoring systems and databases housing variety of data coming from monitors and sensors is rapidly growing. In addition to existing types of network monitors located mostly at distribution transformer substations, deployment of smart meters at end-users' premises will drastically increase the number of real-time data sources (as illustrated in Figure 2 [1]). The main problems expected to arise due to the installation of new monitoring sytems are the (un)availability of memory space in database servers and efficient handling of numerous data streams in real time. This could seriously affect the uptake of close to real-time network management actions, such as demand side management (DSM).

Following the expansion of communication systems in the distribution grid, issues arise also with communication performance, i.e. time delay of the signal arrival, throughput of communication lines and quality of the delivered messages [2]. In order to meet the requirements of efficient data collection, transfer and analysis, a lot of research has been focused lately on developing hierarchical stsructure of data collection points [3]. One of the solutions to these challenges would be the prioritisation of data, i.e., exclusion of redundant data types from data collection systems. Furthermore, appropriate sampling rate should be adopted for each data type in order to reduce the size of stored data streams while preserving the accuracy of information contained within retained data.

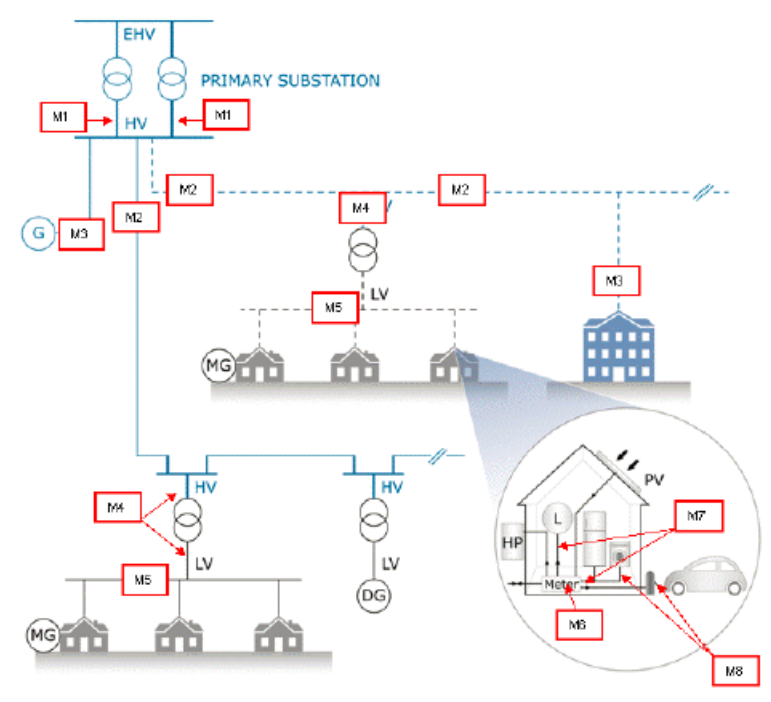

Figure 1 Monitoring devices in future distribution network (adopted from [1])

In order to establish data requirements for the efficient distribution network analysis, one should first examine what types of information are needed at the moment and what might be needed in the future, i.e., in a time frame of 10-20 years. The latter question is particularly important as it should appropriately account for all the novelties that future smart distribution networks will bring. Therefore, there should be a clear perception of future electricity market actors, their functionalities and assets that will be used within these networks. This knowledge can then be used to identify the type(s) of data that will have to be collected in the future.

This paper starts by discussing the data requirements for efficient control and management of future power networks with the emphasis on DSM and compares the data requirements with presently available or routinely 
collected data by distribution system operators (DSOs). It then presents an overview of the technical specifications of some of the typical commercially available smart meters and discusses the possibilities of information retrieval from the data provided by smart meters. Finally, it illustrates to what extent the existing smart meters can support DSM and identifies the functionalities that they should have in order to facilitate advanced DSM in future power networks.

\section{Currently available data}

In order to analyse the suitability of currently available data for the extraction of required information about the network performance, it is essential to consider types of data collected by distribution utilities at the moment. The existing substation monitoring devices are most commonly collecting some of the following data:

- basic measurements: voltage and current magnitude, real power, reactive power, power factor, apparent power, phase sequence, voltage phase angle, current phase angle, neutral current;

- power quality data: voltage sags and swells, voltage and current harmonic distortion per phase, total harmonic distortion;

- asset status: power transformer tap position, breaker status;

- fault data: number of outages, date and time of the last outage, cumulative power outage time

These data are collected for a range of applications crucial for distribution system studies. For example, load flow has to be performed over accurate data in order to calculate voltage profiles at supply points and load in the distribution lines; in cases of non-monitored buses, network state estimation is performed over available data; power quality data and fault data are the main indicators of network reliability, and could facilitate, as indicated by some recent research [4], prediction of fault locations.

The above mentioned data are collected with various time steps and using different averaging periods, depending on the purpose. Averaging period is typically longer than sampling period and only representative, averaged data are saved in order to reduce data storage. If the averaging period is too long, it decreases the possibility of assessing the dynamics of the phenomena considered [5]. As an example, averaging period has shown high influence on calculation of losses in the network. The errors greater than $20 \%$ were observed in calculation of the losses in an LV network when the losses were estimated using demand data averaged over $15 \mathrm{~min}$ period [6]. The level of the under-estimate, i.e., the error, is affected by the demand profile, averaging period and aggregation level.

\section{Data Requirements in Future Distribution Networks}

One of the main features of future distribution grid with a very large number of smart meters deployed, will be the extensive collection of consumption data from the end-users. The overall aim of the smart metering system is to enable two-way communication between suppliers and end-users. In such environement, the electricity suppliers could pass on the dynamic (daily and seasonal) change of electricity price to customers, who would then be incentivised to save energy and make savings to both themselves and suppliers [7]. Even though there are many smart meters installed in residential properties throughout Europe, smart meter data have so far been collected only in limited number of trial installations at pilot sites [1]. For instance, by the end of 2014, only about $5 \%$ of the electricity meters in operation in the UK were smart meters - the rest were traditional meters [8].

Some authors [5] propose that smart meters also need to embed local data analysis capabilities, since sending huge datasets (for millions of customers) along the communication channels exceeds the current capacity. In addition to this, smart meters are still not considered to be suitable for on-line monitoring of distribution networks for control purposes due to high data latency (time needed to collect and store data) of the national communications system which is chosen in some cases to collect smart meter data [1].

Another important use of smart meters is to enable automatic DSM from the distribution system operator's (DSO) or aggregator's side. Taking as an example the communication protocol proposed by [9], the DSO first receives information about the transmission network needs from the transmission system operator (TSO), e.g. for day-ahead, and information from aggregators about available (forecasted) flexibility. Based on this information, the DSO makes a schedule for the following day and sends it to the both parts. Since this application involves time shifting of home appliance usage, it also requires information about the number of occupants in a household, their lifestyle, needs and daily routines. These types of information have usually been acquired through customer surveys which are time demanding and of limited accuracy. Following these, a very useful information would be the percentage of controllable loads in an area (street, aggregation point, country district), in order to have a spatial overview of controllability, i.e. potential flexibility in the distribution network.

Weather condition and its influence on customers' behaviour, i.e. daily load profiles, also play an important role in planning DSM activities. That is why weather data presents the basic data type needed for any demand forecast application. Also, data about operational characteristics of devices under different environmental conditions (e.g. heating and air conditioning) can 
provide information on types of appliances that might be controlled in the future as a part of DSM services. This is particularly the case for geographical areas with extreme weather conditions.

Implementation of modern appliances, e.g. heat pumps, also brings a need for additional information to be collected, such as the average installed power per household in an area. If the existing electrical installation is not designed to accommodate future increase in load, the size of the additional investment plays an important role in decision making regarding deployment of these new technologies. Space and water heating account for a big share (usually more than $75 \%$ ) of home energy consumption in Europe, except in the southern part [10]. The UK government, for example, estimates that the country could have 20 million new heat pumps installed by 2050 .

DSM services highly depend on distribution network reliability. Information is thus required about voltage limits in an area (in the UK, these limits are between $-6 \%$ and $+10 \%$ for $230 \mathrm{~V}$ network, while phase imbalance should not exceed $1.3 \%$ [11]), possible distribution network topology changes and longer-term change in demand, as well as fault level of distribution grid assets in an area [1]. These data facilitate appropriate decision making regarding asset management in the network, which is essential for ensuring reduction in maintenance costs in distribution system utilities.

The state-of-the-art information in terms of data requirements in distribution network is summarised in Table 1. Shaded fields refer to data types that are not commonly collected, thus are presently unavailable, but that would drastically improve the quality of retrieved information if made available.

There are several types of data needed for appropriate DSM actions - primarily, data about the amount of controllable loads in an area, which gives information about potential flexibility of end-users. These data can at this point be collected through customer surveys, but they might also be provided by smart meter data, if this functionality was enabled.

Table 1 State-of-the-art information and data needs in distribution network analysis

\begin{tabular}{|c|c|c|c|}
\hline $\begin{array}{l}\text { Information (knowledge) } \\
\text { needed }\end{array}$ & Data collected & Collection time step & Data group \\
\hline \multirow{5}{*}{$\begin{array}{c}\text { Short-term load } \\
\text { forecasting (including } \\
\text { decomposition) at } \\
\text { primary } \\
\text { substation/aggregator } \\
\text { level to facilitate the } \\
\text { process of demand } \\
\text { response }\end{array}$} & Voltage, real and reactive power & $1 \div 30 \mathrm{~min}$ & \multirow{5}{*}{1} \\
\hline & The amount of controllable electrical loads per aggregation & $30 \min \div 1 \mathrm{~h}$ & \\
\hline & Weather data & $30 \min \div 1 \mathrm{~h}$ & \\
\hline & $\begin{array}{l}\text { Customer's willingness to participate in demand response } \\
\text { Home appliances specifications }\end{array}$ & $30 \min \div 1 \mathrm{~h}$ & \\
\hline & Pricing data & $30 \mathrm{~min} \div 1 \mathrm{~h}$ & \\
\hline \multirow{2}{*}{$\begin{array}{c}\text { Short-term distributed } \\
\text { generation forecast } \\
\text { (including } \\
\text { decomposition) at } \\
\text { primary } \\
\text { substation/aggregator } \\
\text { level to facilitate the } \\
\text { process of demand } \\
\text { response }\end{array}$} & $\begin{array}{l}\text { Voltage, real and reactive power } \\
\text { Weather data }\end{array}$ & $\begin{array}{l}1 \div 30 \mathrm{~min} \\
30 \mathrm{~min} \div 1 \mathrm{~h}\end{array}$ & \multirow[b]{2}{*}{2} \\
\hline & $\begin{array}{l}\text { Amount of distributed energy resources (PVs, small wind turbines, } \\
\text { storage) in an area }\end{array}$ & I & \\
\hline $\begin{array}{l}\text { Fault location } \\
\text { identification (fault } \\
\text { detection) }\end{array}$ & $\begin{array}{l}\text { Current and voltage waveforms } \\
\text { Network topology } \\
\text { Type of fault (historical data) } \\
\text { Relay and breakers states } \\
\text { Power outage time }\end{array}$ & $\begin{array}{c}\sim \mathbf{m s} \\
/ \\
/ \\
\sim \mathbf{m s} \\
\quad /\end{array}$ & 3 \\
\hline $\begin{array}{l}\text { Condition assessment / } \\
\text { Asset management }\end{array}$ & $\begin{array}{l}\text { Age of assets } \\
\text { Monitoring data acquired during the operation } \\
\text { Number of faults } \\
\text { Network topology }\end{array}$ & I & 4 \\
\hline $\begin{array}{l}\text { Electricity price } \\
\text { formation and price } \\
\text { spikes forecast }\end{array}$ & $\begin{array}{l}\text { Electricity market data } \\
\text { Historical data on consumption } \\
\text { Weather data }\end{array}$ & $\begin{array}{l}30 \min \div 1 \mathrm{~h} \\
30 \min \div 1 \mathrm{~h} \\
30 \mathrm{~min} \div 1 \mathrm{~h}\end{array}$ & 5 \\
\hline $\begin{array}{l}\text { Power quality detection } \\
\text { for power system } \\
\text { disturbance }\end{array}$ & Voltage and current waveforms & $\sim \mathrm{ms}$ & 6 \\
\hline
\end{tabular}


Having the information about the number of customers willing to participate in DSM in certain time frame could give the amount of actual load controllability. This controllability would be equal to potential controllability only if all the controllable customers were participating in demand response, otherwise it is smaller. Signals related to customer's willingness to participate in a DSM action could be sent through twodirection communication between a smart meter and the DSO/aggregator.

A complementary piece of information would be the one about smart home appliances specifications in an area. This would be required in cases of event/state based measurements of appliances usage, where only signals about operation mode of appliances (e.g. on/off) are sent to the data concentrator. The operational data (consumption in different operation modes) about these appliances would facilitate calculation of the load composition of overall consumption, depending on which appliances are turned on and working at each time step. In this way, it would be possible for the network operator to have (close to) real-time information about the number of controllable devices and the amount (in $\mathrm{kW}$ ) of controllability, i.e. flexibility. The aforementioned types of information would all together lead to a highly accurate estimation of not only possible, but also available end-users' flexibility in an area.

Measurements of time-varying consumption of each individual appliance in a house, or at least controllable devices, should, in ideal case, include measurements of both active and reactive power of appliances. Amount of distributed energy resources (DER) could also be estimated based on the smart meter records on energy exported, i.e. energy flow from individual users' local generation into the network. This information would be used to calculate possible user's flexibility coming from renewable sources together with the energy reserve from storage units in an area.

\section{Possibilities offered by Smart Meter Data}

There are numerous sources giving information on the benefits smart meters will bring to the end-users. On the other hand, more insight is needed into benefits of smart meter data from the point of view of a network operator, at distribution and transmission level. As stated in official websites about smart meters $[12,13]$, customers will be provided with following advantages:

- Near real-time information on energy use - updated at least every 10 seconds, together with the cost, as well as $\mathrm{CO}_{2}$ emission

- Better management of energy usage, saving money and reduction of $\mathrm{CO}_{2}$ emission

- Billing based on the actual consumption, not estimation
- Easier switching to other suppliers with different tariffs

- Access to historical consumption data

Customers will have the freedom to choose whether they want the measurement data to be sent monthly, daily or every 30 minutes [13]. This however, will cause difficulties to applications requiring the same sampling step of the incoming data streams which are to be aggregated and further processed.

The meter should be recording active and reactive energy import and export and keep all the information in its own data store [14]. Based on specifications given in $[15,16]$, smart meter accuracy of measurements complies with class 1 (error limits $\pm 1.5 \%$ ) or class 2 (error limits $\pm 2.5 \%$ ) for active power/energy and class 2 for reactive power/energy. There are multiple channels for load profile recording (usually 2 or 4 channels), as well as for appliance profile recording ( 8 channels). Profiling period can be $15,30,60$ minutes or one day.

According to technical specifications required by the UK Government's Department of Energy and Climate Change (DECC) [14], smart meters should also measure average rms voltage and record cases of over or under voltage (i.e. when the value is over the 'average rms over-voltage threshold' or under the 'average rms under-voltage threshold', respectively). It should also detect voltage sags and swells. There should be a load switch for enabling/disabling supply, and limiting power consumption. Data storage is required to keep minimum of 13 months of active energy imported and 3 months of active energy exported and reactive energy imported and exported.

\section{Discrepancies between Information Needs and Actual Data Availability}

Table 2 presents discrepancies between present smart meters' features and data provided, and information needs for management and control of future distribution network.

As illustrated in Table 2, most of the present or foreseen data needs can be, to smaller or larger extent, met by smart meter data. The following functionalities/actions would be greatly enhanced by the use of smart meter measurements:

- Load forecasting could be applied to lower levels of aggregation, because it would follow daily pattern of customers in a specific geographic area. This could further facilitate local DSM programs.

- The accuracy of state estimation could be largely enhanced with the reliance on low-level consumption (real and reactive power) data, which are presently hardly accessible and hence replaced with pseudo-measurements. 
- Fault detection could be highly improved with smart metering of voltage enabling the network operator to receive notifications about interruptions in supply much faster than usual (distribution network operator commonly receives fault notifications from customers service).

- Since the majority of presently installed smart meters don't have the functionality of monitoring individual appliances (these measurements have only been done in limited number of test sites), estimation of the amount of controllable loads can at this point be made only by using some data mining and machine learning methods. Voltage measurements at end-user level can be used, besides facilitating detection of faults at measurement point, to complement types of data (real and reactive power) needed for load disaggregation process at aggregation point [17]. In this way, the state estimation could be performed with still limited, but improved accuracy compared to present practice, using smart meter data instead of measurements at bus points.

- The amount of flexibility offered by DER could also be "tracked" thanks to smart meters measuring energy flow in both directions.

There are two main areas of interest that are currently not covered by smart meters. One of them is the information about customers' willingness to participate in DSM actions. As previously mentioned, this information would reduce the uncertainties in the actually available load flexibility in case of voluntary demand response contracts between customers and the network operator, where customers react to demand response signals (i.e. incentives to shift or reduce their consumption). Although smart meters do not have this feature, signals about confirmation of participation in DSM could also be sent through other devices, e.g. smart phones or personal computers.

The other missing piece is the information about individual types of appliances that customers in an area are using. This is required in order to reduce uncertainties in DSM programs. An invasive solution to this would be upgrading the current smart meters to the level of appliance-based monitoring. A non-invasive solution was described in [18] proposing device level load monitoring (DLLM) - the method is based on formation of database with recordings of active load profiles of different appliances. In this way, customers would be able to select, from a library of profiles on offer, the one that fits their appliance best and enable the network operator to perform disaggregation based on the total load measurements.

As the issue of disaggregated load attracts a lot of intention in the area of future DSM programs, a probabilistic approach was developed in [17] by application of data analytics and pattern recognition tools over total consumption data in order to retrieve information about consumption of individual categories of appliances. This gave as an output a probabilistic estimation of the amount of controllable and uncontrollable load within total load. The accuracy of this method can be improved by inclusion of more realistic data in the machine learning process.

Table 2 Smart meter data suitability for future distribution system data and information needs

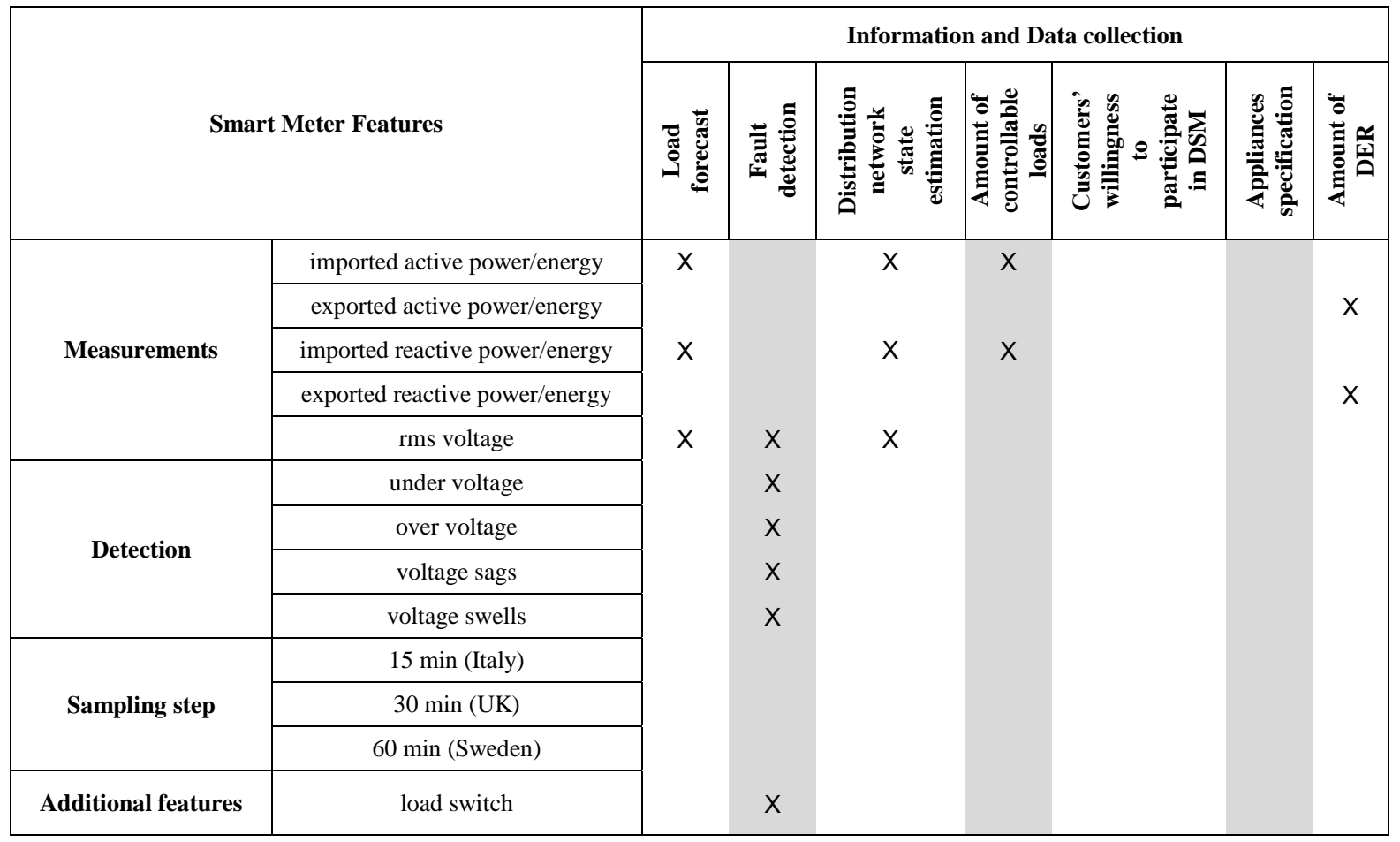




\section{Possible Issues with Smart Meter Data}

Even though application of smart meters offers significant advantages in terms of improved accuracy of various functionalities needed for DSM, there are still some issues that need to be resolved. Since the customers will decide on the frequency of sending their load profiles to the data concentrator, data streams will not be coming with the same time steps. This will result in additional missing data, considering that some data might be missing anyway due to malfunction of devices or communication failures, and the need for application of some data imputation methods, i.e. data generation. Influence of this data pre-processing on the accuracy of aggregated data is yet to be investigated. Furthermore, considering that all measurements contain certain amount of noise, the appropriate filtering of measured signals is required. The level of filtering and accuracy of filtered data will depend on the type of application that the data will be used for, so adaptive filtering techniques need to be developed.

For on-line applications, such as state estimation and demand response, higher granularity of data is needed (e.g. minute based), so 30 or 60-minute based sampling steps that are presently most widely used, may not be appropriate. Also, in order to reduce the computation time, it is preferable to receive instant power data from smart meters, instead of energy data over a time frame. Finally, for any kind of transient stability analysis that will include studies of dynamic response of demand [17], granularity of power samples should be even higher, in the range of seconds or even milliseconds. In this case signal latency and synchronised sampling become an important issue, in addition to significant increase in amount of data that would need to be processed.

\section{Conclusion}

This paper presented state-of-the-art data requirements for present and future distribution system operator's needs. A comparative analysis identified discrepancies between required and available data coming from monitors that are currently used in distribution networks. Most of the present data needs and data types foreseen for the future distribution network studies can be covered by the existing monitors. Types of the data that presently typically are not collected include customers' willingness to participate in demand response, amount of controllable loads (including device specifications), and the status of installed DER.

Following the deployment of smart meters in many European countries, possibilities of information retrieval from smart meters' data were also investigated. Analysis shows that present smart meters do not fully comply with the needs of existing DSM programs. This is particularly the cases of voluntary demand response, where the customers willing to participate in a given time frame should be able to send signals of confirmation to the actor performing demand response (DSO or aggregator). A device-based monitoring is another issue requiring more research towards the noninvasive solutions.

Possible obstacles that might arise with the reliance on smart meter data in existing distribution grid operation mainly concern different sampling steps in cases of online data streams aggregation and inappropriately large sampling steps for real-time applications, such as demand response or transient stability studies. Methods of efficient data pre-processing (imputation of missing data, data filtering, and data latency) will need to be developed to mitigate these problems and to assess the effects of these on the accuracy of the output for different types of applications.

\section{Acknowledgements}

This research is partly supported by the EU Horizon 2020 project "Nobel Grid", contract number 646184.

\section{References}

[1] M. Lees, "Enhanced Network Monitoring Report, Customer-led Network Revolution," Northern Powergrid (Northeast) Limited, Northern Powergrid (Yorkshire) Plc, British Gas Trading Limited, University of Durham and EA Technology Ltd., [Online].Available:http://www.networkrevolution. co.uk/resources/project-library2014.

[2] A. Srivastava. Cyber Infrastructure for the Smart Grid, [Online]. Available: https://sgdril.eecs.wsu.edu/files/files/Lesson\%201_ 2_Motivation\%20for\%20the\%20Smart\%20Grid.p df

[3] K. Samarakoon, J. Ekanayake, and N. Jenkins, "Reporting Available Demand Response," Smart Grid, IEEE Transactions on, vol. 4, pp. 18421851, 2013.

[4] L. A. Irwin, "Real experience using power quality data to improve power distribution reliability," Schneider Electric, 2011.

[5] G.Chicco, "A Multi-faceted View on the Characterisation of Electrical Demand," Presentation at the University of Manchester, 2015.

[6] A. J. Urquhart and M. Thomson, "Impacts of Demand Data Time Resolution on Estimates of Distribution System Energy Losses," Power Systems, IEEE Transactions on, vol. 30, pp. 14831491, 2015.

[7] D. S. Kirschen, A. Rosso, M. Juan, and L. F. Ochoa, "Flexibility from the demand side," in Power and Energy Society General Meeting, 2012 IEEE, 2012, pp. 1-6.

[8] "Smart Meters, Great Britain, Quarterly report to end December 2014," Department of Energy and Climate Change, 2015. 
[9] Y. Xiang, L. Junyong, Y. Wei, and C. Huang, "Active energy management strategies for active distribution system," Journal of Modern Power Systems and Clean Energy, vol. 3, pp. 533-543, 2015.

[10] [Online].Available:

http://www.eon.com/en/businessareas/distribution/technology-of-the-future/smartmeters/key-technology-smart-metering.html.

[11] D. F. Frame, G. W. Ault, and S. Huang, "The uncertainties of probabilistic LV network analysis," in Power and Energy Society General Meeting, 2012 IEEE, 2012, pp. 1-8.

[12] "[Online].Available: https://www.smartenergygb.org/en/faqs."

[13] "Smart meter data - A guide to your rights and choices," [Available].Online: http://www.energyuk.org.uk/policy/smart-meters.html.

[14] Smart Metering Equipment Tecnical Specifications, [Online]. Available: https:/www.gov.uk/government/uploads/system/u ploads/attachment_data/file/299395/smets.pdf

[15] [Online]. Available: http://www.rexelenergysolutions.co.uk/media/pdfs /EL09_AS230_Single_Phase_Smart_Meter_Techn ical.pdf

[16] [Online]. Available: http://www.jwsmartmeters.co.uk/Landis-Gyr-E470

[17] Y. Xu, "Probabilistic Estimation and Prediction of the Dynamic Response of the Demand at Bulk Supply Points," PhD thesis, School of Electrical and Electronic Engineering, University of Manchester, 2015.

[18] W. Kong, Y. Xu, Z. Dong, D. J. Hill, J. Ma, and C. $\mathrm{Lu}$, "An extended prototypical smart meter architecture for demand side management," in Industrial Informatics (INDIN), 2015 IEEE 13th International Conference on, 2015, pp. 1008-1013. 